\title{
Measurement of X-ray CTR Signals from GaN/GaInN/GaN at High Temperatures Using Newly Developed Measurement System
}

\author{
Y. Takeda, T. Mizuno, H. Kamiya, K. Ninoi, and M. Tabuchi* \\ Department of Crystalline Materials Science, Nagoya University, \\ Fax: 81-52-789-3239, e-mail: takeda@numse.nagoya-u.ac.jp \\ *Venture Business Laboratory, Nagoya University \\ Fax: 81-52-789-5448, e-mail: tabuchi@vbl.nagoya-u.ac.jp \\ Furo-cho, Chikusa-ku, Nagoya 464-8603, Japan
}

\begin{abstract}
A combined system of laboratory X-ray CTR scattering measurement and MOVPE growth facility was set up and CTR measurement on $\mathrm{GaN} / \mathrm{GaInN} / \mathrm{GaN}$ heterostructure was conducted at room temperature and high temperatures up to $1000{ }^{\circ} \mathrm{C}$. Clear CTR signals and composition profiles were obtained even at $1000^{\circ} \mathrm{C}$.

Key words: CTR, MOVPE, Laboratory X-ray, GaN/GaInN/GaN, High temperature
\end{abstract}

\section{INTRODUCTION}

In our previous papers, we reported the design and setup of the laboratory level X-ray CTR (crystal truncation rod) scattering measurement system and successful measurement of the CTR signals from $\mathrm{InP} / \mathrm{GaInAs} / \mathrm{InP}$ and $\mathrm{GaN} / \mathrm{GaInN} / \mathrm{GaN}$ heterostructures at room temperature within $100 \mathrm{~min}$. The improvements made were to use a multi-layered focusing mirror and an asymmetry-cut double-crystal to collect and squeeze the X-rays from the rotating target $\mathrm{X}$-ray source and to use slits between the sample and the detector to avoid stray X-rays [1-2].

Our intention is to investigate the growth process of, for example $\mathrm{GaN} / \mathrm{GaInN} / \mathrm{GaN}$, using the monolayer- sensitive X-ray CTR scattering. The MOVPE (metalorganic vapor phase epitaxy) reactor with two Be windows was installed to the laboratory X-ray system [1].

In this paper, we report the proper operation of the measurement system with the reactor installed and the X-ray CTR scattering measurements on the $\mathrm{GaN} / \mathrm{GaInN} / \mathrm{GaN}$ heterostructure at as high as $1000^{\circ} \mathrm{C}$.

\section{REACTOR AND STAGE}

Though a picture of the X-ray system and installed reactor was shown in our previous paper [1], some details of the reactor structure and the XYZ-stage are described here. Fig. 1 shows the side view and front

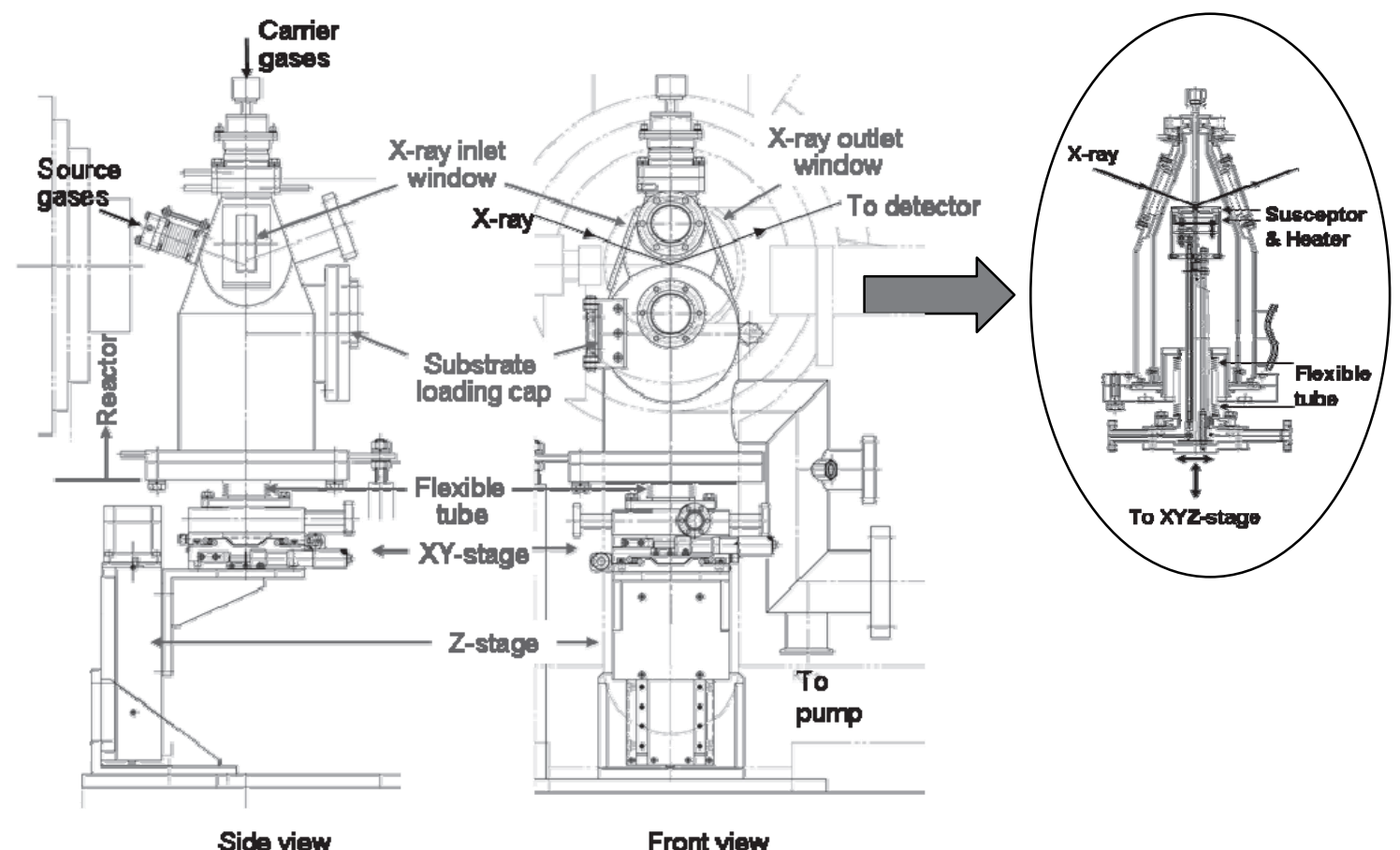

Fig. 1 Side view and front view of reactor and XYZ-stage for positioning the susceptor surface to the X-rays, while the reactor is fixed. Be windows are used for the X-ray path through the reactor. The inset is to show the susceptor and heater inside the reactor. 
view of the reactor and stage. The reactor part is fixed at a proper position to the X-ray source and detector and there is no freedom for the reactor to be adjusted because pipes for gas introduction and tubes for pumping are fixed to reactor.

To adjust the sample position against the incoming and outgoing X-rays, an XYZ-stage was set to move the susceptor and heater part through a flange connected by a flexible tube to the reactor as shown in the inset of Fig. 1. The Z-stage is essential for sample positioning and is tough enough to support the $\mathrm{XY}$-stage from the pulling-up force when the reactor was pumped to vacuum. The thickness of the $\mathrm{Be}$ window was $0.3 \mathrm{~mm}$. The intensity lowered to $85 \%$ of the original one due to the two Be windows.

\section{HIGH TEMPERATURE MEASUREMENTS \\ $3.1 \mathrm{~S} / \mathrm{B}$ ratio}

First of all, it is well anticipated that the thermal diffuse-scattering (B: background) increases and the CTR scattering intensity ( $\mathrm{S}$ : signal) decreases at higher temperatures. To find whether the S/B ratio is high enough to measure the CTR scattering profile at higher temperatures, we measured the temperature dependence of the CTR peak intensity (at around 1.95 in Fig. 4) and thermal diffuse-scattering intensity using the $\mathrm{GaN} / \mathrm{GaInN} / \mathrm{GaN}$ wafer on sapphire substrate as shown in Fig. 2. In the temperature-change process it was necessary to wait for about $50 \mathrm{~min}$ until the susceptor and heater expansions were stabilized. The sample height was adjusted by the Z-stage.

The temperature dependence of the $\mathrm{S} / \mathrm{B}$ ratio is shown in Fig. 3. The experimental data are shown by $(\bullet)$. The calculation of $\mathrm{S}$ was made using a standard diffraction intensity where the Debye-Waller factor

$$
\mathrm{S} \propto \exp (-2 \mathrm{M})
$$

is the most temperature-dependent. $\mathrm{M}$ is a function of $\Theta_{D} / T$ where $\Theta_{D}$ is the Debye temperature. The thermal diffuse-scattering intensity (B) is proportional to the temperature $\mathrm{T}$ and the Debye-Waller factor as

$$
\mathrm{B} \propto \mathrm{T} \cdot \exp (-2 \mathrm{M})
$$

when $\mathrm{T}>\Theta_{\mathrm{D}}$. Then, $\mathrm{S} / \mathrm{B} \propto 1 / \mathrm{T}$ when $\mathrm{T}>\Theta_{\mathrm{D}}$ and $\mathrm{S} / \mathrm{B}=$ Constant when $\mathrm{T}<\Theta_{\mathrm{D}}\left(\Theta_{\mathrm{D}}=600 \mathrm{~K}\right.$ was used. $)$. In the comparison, the $\mathrm{S} / \mathrm{B}$ values by experiments and by calculation were normalized at RT $(300 \mathrm{~K})$. Considering those temperature dependent factors and using the intensity at RT as the initial value, the temperature dependence of $\mathrm{S} / \mathrm{B}(\bullet)$ was calculated.

At $1000^{\circ} \mathrm{C}(1273 \mathrm{~K})$ the ratio decreased to half at RT. The decrease of the S/B ratio is mostly caused by the increase of $\mathrm{B}$ that is the thermal diffuse-scattering.

Fig. 4 shows the CTR spectra measured at RT for $100 \mathrm{~min}$, at $1000^{\circ} \mathrm{C}$ for $100 \mathrm{~min}$, and at $1000^{\circ} \mathrm{C}$ for 200min. The backgrounds (mostly due to the thermal diffuse-scattering) are subtracted. To increase the S/B ratio at $1000^{\circ} \mathrm{C}$ the $\mathrm{CTR}$ scattering was measured for 200min. The spectrum quality looks better than that at

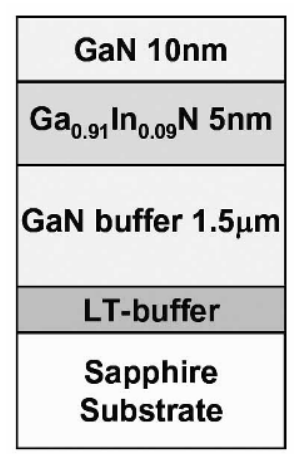

Fig. 2 Sample structure to measure the temperature dependence of $\mathrm{S} / \mathrm{B}$ ratio.

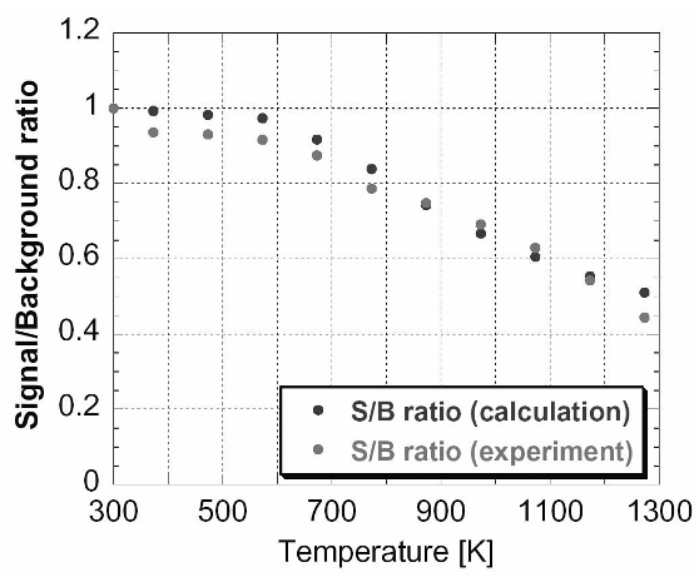

Fig. 3 The temperature dependence of S/B ratio from the sample $(\bullet)$ shown in Fig. 2. $(\bullet)$ is a calculation changing the temperature dependent parameters in the CTR scattering and the thermal diffusescattering. The intensities at RT $(300 \mathrm{~K})$ were used as initial values.

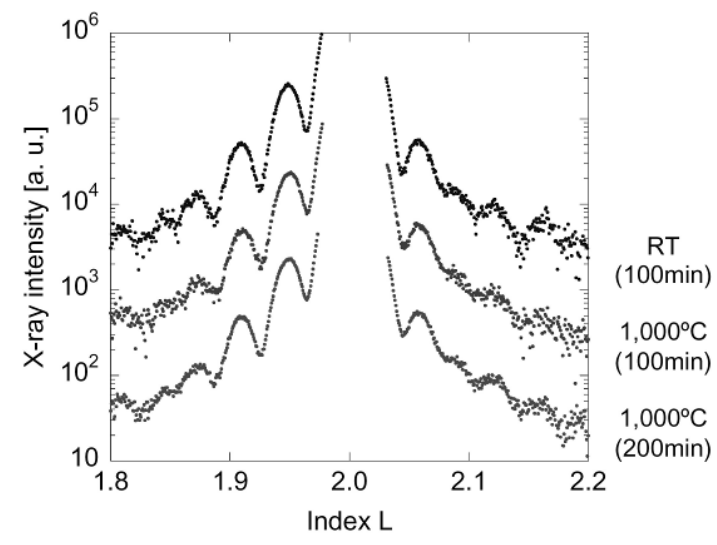

Fig. 4 CTR spectra at RT measured for $100 \mathrm{~min}$, at $1000^{\circ} \mathrm{C}$ for $100 \mathrm{~min}$, and at $1000^{\circ} \mathrm{C}$ for $200 \mathrm{~min}$. Background (thermal diffuse-scattering) is subtracted. 
RT for $100 \mathrm{~min}$

\subsection{Spectra at high temperatures and curve-fitting}

Two different wafers, as shown in Fig. 5, were used to measure the temperature dependence of the CTR spectra. Measured CTR spectra at several temperatures and at RT before and after the heating are shown in Fig. 6 in the case of $\mathrm{GaN} / \mathrm{GaInN} / \mathrm{GaN}$ on sapphire substrate. Fig. 7 is the similar spectra from $\mathrm{GaInN} / \mathrm{GaInN} / \mathrm{GaInN}$ on $\mathrm{GaN}$ substrate. Gray lines in both figures are the best-fit curves.

The fitting results were better in the case of GaInN/GaInN/GaInN on GaN substrate. It is visually clear and also indicated by the R-factor values in both figures. There was curving of the wafer of $\mathrm{GaN} / \mathrm{GaInN} / \mathrm{GaN}$ on sapphire substrate probably due to the difference in the thermal expansion coefficients between $\mathrm{GaN}$ and sapphire, even at RT, and should change with temperature. In the calculation those effects were not included (curving should be

\begin{tabular}{|c|}
\hline GaN 10nm \\
\hline $\mathbf{G a}_{0.88} \mathrm{In}_{0.12} \mathrm{~N} 5 \mathrm{~nm}$ \\
\hline GaN buffer $1.5 \mu \mathrm{m}$ \\
\hline LT-buffer \\
\hline $\begin{array}{l}\text { Sapphire } \\
\text { Substrate }\end{array}$ \\
\hline
\end{tabular}

\begin{tabular}{|c|}
\hline$G a_{0.98} I n_{0.02} N 10 n m$ \\
\hline$G a_{0.88} I n_{0.12} N 3.5 n m$ \\
\hline$G a_{0.98} I n_{0.02} N 10 n m$ \\
\hline $\begin{array}{c}\text { GaN } \\
\text { Substrate }\end{array}$ \\
\hline
\end{tabular}

Fig. 5 Two different wafers (left; $\mathrm{GaN} / \mathrm{GaInN} / \mathrm{GaN}$ on sapphire substrate and right; GaInN/GaInN/GaInN on $\mathrm{GaN}$ substrate), used for temperature dependence measurements of the CTR spectra.
Fig. 6 CTR spectra from $\mathrm{GaN} / \mathrm{GaInN} / \mathrm{GaN}$ on sapphire substrate at several temperatures and at RT before and after heating. Gray curves are best-fit curves to each spectrum. R-factor indicates the fitting quality.
Fig. 7 CTR spectra from $\mathrm{GaInN} / \mathrm{GaInN} / \mathrm{GaInN}$ on $\mathrm{GaN}$ substrate at several temperatures and at RT before and after heating. Gray curves are best-fit curves to each spectrum. R-factor indicates the fitting quality.

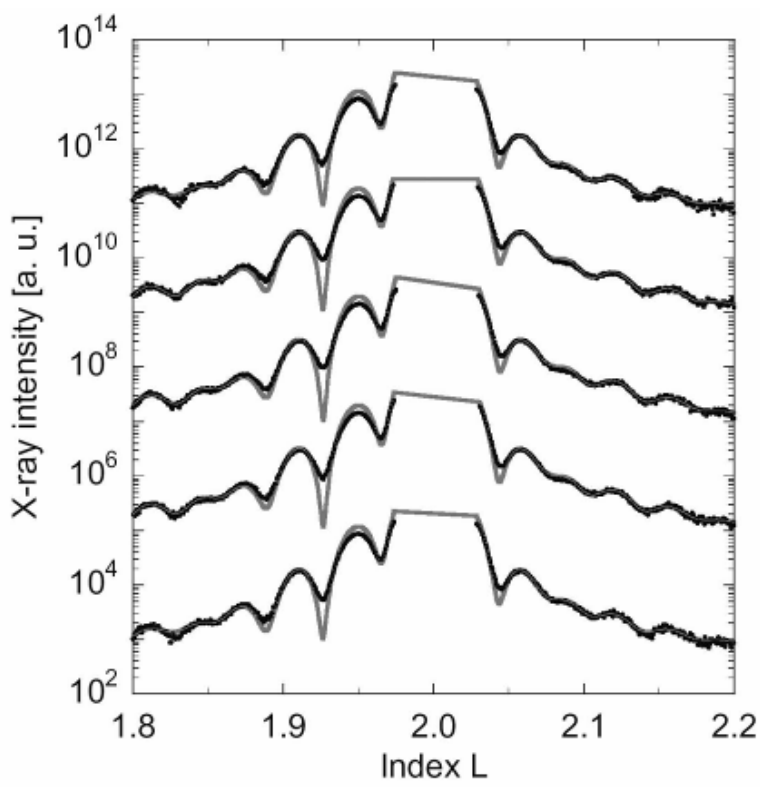

RT(After heating) $\mathrm{R}$-factor $=0.016$

$1000^{\circ} \mathrm{C}$

$R$-factor $=0.015$

$800^{\circ} \mathrm{C}$

$\mathrm{R}$-factor $=0.015$

$600^{\circ} \mathrm{C}$

R-factor $=0.014$

RT(Before heating)

$R$-factor $=0.016$

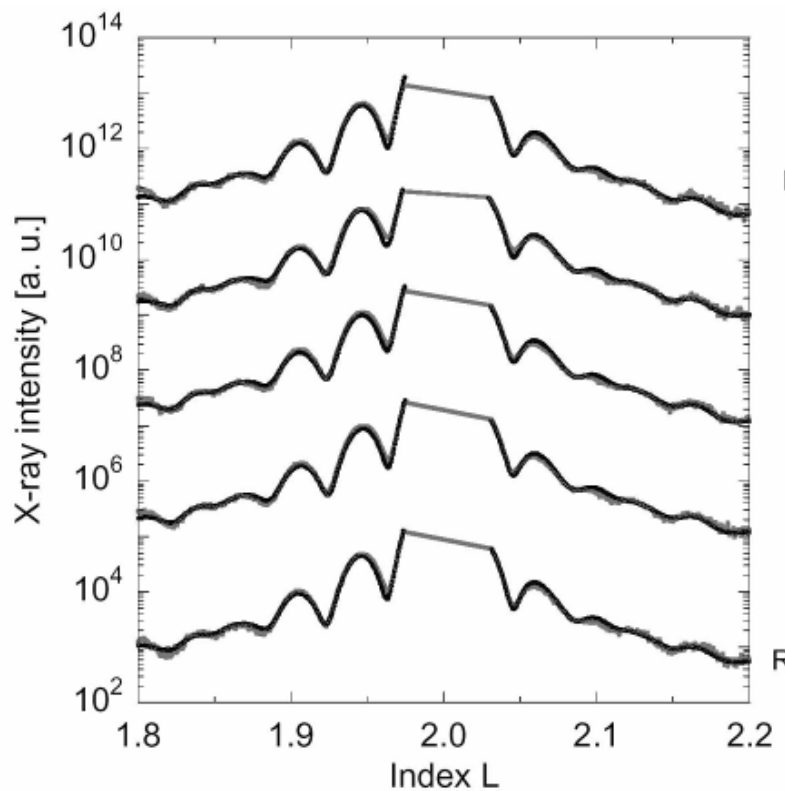

$\mathrm{RT}$ (After heating) $R$-factor $=0.012$

$800^{\circ} \mathrm{C}$

R-factor $=0.011$

$600^{\circ} \mathrm{C}$

$\mathrm{R}$-factor $=0.010$

$400^{\circ} \mathrm{C}$

$R$-factor $=0.010$

RT(Before heating) $R$-factor $=0.012$ 
temperature-dependent since the velocity of the misfit dislocations is also temperature-dependent) and they may affect the fitting quality.

\subsection{Composition profiles}

Indium (In) composition profiles are shown in Figs. 8 and 9. Fig. 8 shows In composition profiles in $\mathrm{GaN} / \mathrm{GaInN} / \mathrm{GaN}$ on sapphire substrate at RT before heating and at $1000^{\circ} \mathrm{C}$ obtained from Fig. 6. Fig. 9 shows In composition profiles in GaInN/GaInN/GaInN on $\mathrm{GaN}$ substrate at RT before heating and at $800^{\circ} \mathrm{C}$ obtained from Fig. 7.

In both cases, there looks no significant difference between profiles at RT and at high temperatures. In compositions at peak are much lower, in both cases, than those designed (In compositions in Fig. 5 are those

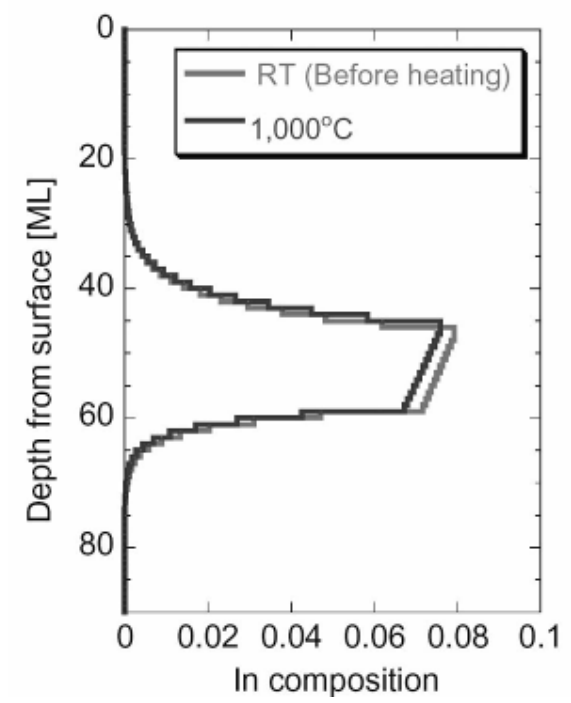

Fig. 8 In composition profiles in $\mathrm{GaN} / \mathrm{GaInN} / \mathrm{GaN}$ on sapphire substrate at RT before heating and at $1000^{\circ} \mathrm{C}$ obtained from Fig. 6.

\section{SUMMARY}

A detailed structure of the reactor and the XYZ-stage installed in the X-ray diffraction measurement system was described, and the proper operation of the whole measurement system on the $\mathrm{Ga}(\mathrm{In}) \mathrm{N} / \mathrm{GaInN} / \mathrm{Ga}(\mathrm{In}) \mathrm{N}$ heterostructure at as high as $1000^{\circ} \mathrm{C}$ was reported. Though there are several ambiguities in the analysis due to strain in the wafer, very different In profiles were obtained for the case of $\mathrm{Ga}(\mathrm{In}) \mathrm{N} / \mathrm{GaInN} / \mathrm{Ga}(\mathrm{In}) \mathrm{N}$ on sapphire and that on $\mathrm{GaN}$. values designed.). This difference has been our experience in other many samples. Our understanding is that the In composition is determined from X-ray diffraction, XPS, and/or AES on thick layers. However, in a thin (several $\mathrm{nm}$ ) layers, In is not fully incorporated from gas phase to solid phase. There observed, as in Fig. 7 and 8, a tendency that In increases to the growth direction.

This effect is our first target to investigate using the measurement system described in this paper.

The safety facilities are being designed and installed just in case the Be windows abruptly break at a raised susceptor temperature in a hydrogen and metalorganic source gases.

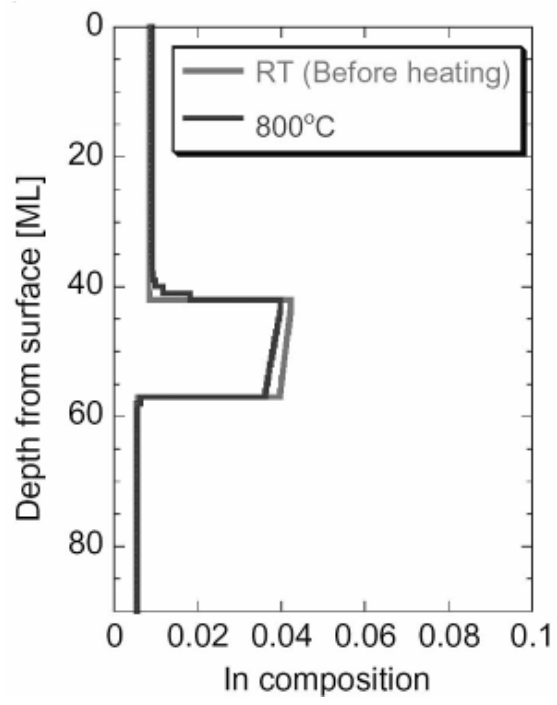

Fig. 9 In composition profiles in GaInN/GaInN/GaInN on GaN substrate at RT before heating and at $800^{\circ} \mathrm{C}$ obtained from Fig. 7.

This work was supported in part by the Grant-in-Aid for Scientific Research (S) \#18106001 and (B) \#19360006 from the Japan Society for the Promotion of Science.

\section{REFERENCES}

[1] Y. Takeda, Y. Maeda, T. Mizuno, and M. Tabuchi, Trans. Mat. Res. Soc. Jpn., 33, 547-550 (2008).

[2] Y. Maeda, T. Mizuno, A. Mori, M. Tabuchi, and Y. Takeda, Trans. Mat. Res. Soc. Jpn., 33, 591-594 (2008).

(Received July 14, 2009;Accepted August 31, 2009) 